\title{
Lector in ffabla. Estructuras del Setenario de Alfonso X el Sabio (I)
}

\section{Lector in ffabla. Structures of Alfonso X the Wise's Setenario (I)}

(DD Johan Puigdengolas

johan.puig@gmail.com

Universidad de Toulouse II - Jean Jaurès, Francia

Recepción: 23 Abril 2021

Aprobación: 15 Septiembre 2021

Publicación: 01 Noviembre 2021

Cita sugerida: Puigdengolas, J. (2021). Lector in ffabla. Estructuras del Setenario de Alfonso X el Sabio (I). Aivar, 21(34), e104. https://doi.org/10.24215/18524478e104

\begin{abstract}
Resumen: El siguiente trabajo se centra en el papel de la lectura en el proceso de desciframiento y de comprensión del Setenario de Alfonso X. A partir de varios enfoques, se analizarán las especificidades del procedimiento de codificación que es el "setenario" así como sus significaciones para el lector.

Palabras clave: Setenario, Alfonso X, Poética, Lectura, Historia intelectual.

Abstract: This article focuses on the role of reading in the process of deciphering and understanding Alfonso $\mathrm{X}$ the Wise's Setenario. Through several perspectives, the particularities and significations that the literary device called "setenario" has for the reader will be analysed.
\end{abstract}

Keywords: Setenario, Alfonso X, Poetics, Reading, Intellectual History.

"Modus legendi in dividendo constat. Divisio sit et partitione et investigatione. Partiendo dividimus quando ea quae confusa sunt distinguimus. Investigando dividimus quando ea quae occulta sunt reseramus."

Hugo de San Víctor, Disdascalicon, VI, 12.

Leer el Setenario supone abstraerse de los debates en torno a su estructura, su datación y su adscripción en la dinámica intelectual que caracteriza la labor del monarca. ${ }^{1}$ Por su estado de conservación, así como la falta de estudios sintéticos, ninguna de estas cuestiones ha sido zanjada, pero no han de impedir la consulta de la obra ni la valoración de su contenido, que, en definitiva, ha sido muy poco estudiado desde el punto de vista literal. Releer el Setenario, dejándose guiar por los movimientos de lectura que impone, parece una buena manera de contribuir a su reevaluación.

El Setenario se ofrece al lector moderno como un borrador inacabado del que se han conservado varias copias y, posiblemente, varias versiones. ${ }^{2}$ Adentrarse en la lógica de este work in progress (Ruiz García, 2006, pp. 375-377) supone transigir con su carácter incompleto y transitorio para lograr distinguir las vacilaciones e indicios de estructuración que contiene. Nuestro propósito, a través de una serie de estudios, será identificar 
estas huellas de composición y evidenciar, en la medida de lo posible, los procedimientos y las estructuras que conforman el discurso y que pueden guiar al lector. ${ }^{3}$

Amén un guiño al famosísimo ensayo de Umberto Eco (1979), la fórmula lector in ffabla remite a una afirmación que encontramos al final de la ley X del Setenario, y que tiene que ver con la composición de la obra:

Et nos don Alffonso, desque ouymos este libro conpuesto e ordenado, pusiémosle nonbre segunt que entendiemos que conuiníe a la natura de las rrazones e a la manera de ffabla. (Alfonso X, ed. 1984, X, p. 25, 1. 18-20) ${ }^{4}$

Esta justificación sugiere varios comentarios. Primero, el rey afirma que el libro fue terminado, lo cual, a la luz de los elementos materiales de los que disponemos, parece improbable. Segundo, afirma que eligió un título acorde, de forma casi analógica, a la materia que contiene la obra, así como al discurso (ffabla) que desarrolla. Estas premisas ontológicas y retóricas se materializan en una segunda justificación, que sigue inmediatamente: "Setenario pusiemos nonbre a este libro porque todas las cosas que en él sson van ordenadas por cuento de siete" (Alfonso X, ed. 1984, XI, p. 25, 1. 23-24). La obra lleva, pues, un título remático en la terminología de Genette (1987), es decir un título que remite únicamente a su organización formal.

En efecto, nunca se trata del número siete en el Setenario. No hay ninguna especulación en torno al número siete ni a su valor simbólico, ${ }^{5}$ al menos, ninguna especulación comparable con la introducción tardía de las Siete Partidas, en la cual está asociado a referentes bíblicos. El siete constituye el denominador común de series de realidades parecidas o acopladas. Cada ley, cada fragmento, participa de esta poética de la lista (Eco, 2009), ya que el setenario, adjetivo sustantivado por los redactores, es un procedimiento enumerativo. El uso de la estructura heptalógica parece limitarse al juego verbal y a la obligación formal. Este sistema lleva a una especie de sublimación de los saberes expuestos en la obra que parecen participar de un orden ligado a lo sagrado. La escritura está orientada deliberadamente hacia una forma de hermetismo culto que contribuye al prestigio de las informaciones que contiene la obra y remite a un intertexto cuya extensión y cuyas relaciones exactas con el contenido concreto del Setenario no se han aclarado del todo.

Perona (1988) se ha interesado por dicho intertexto esforzándose por identificar algunas de las fuentes del Setenario. El corpus que ha circunscrito tiene, sin embargo, pocas relaciones con el tratado desde un punto de vista literal. La apreciación de la dimensión simbólica de la obra es problemática. Gutwirth (2005) ha estimado que el setenario no es una estructura inspirada por fundamentos teológicos, sino que reproduce el septennium de las artes liberales, tal como lo afirma la justificación del título en el comienzo de la ley XI. Si bien la inclusión de las artes liberales es un elemento que distingue fundamentalmente el Setenario del doble prólogo de las Siete Partidas, el procedimiento se origina más bien en un programa noético inacabado: "Las vii razones prinçipales de que ssale el nonbre deste libro, a que llaman Ssetenario: Entendimiento Natura - Ssabiduría - Rrazón (...)” (Alfonso X, ed. 1984, XI, p. 26, 1. 1-3). La especial codificación del Setenario plantea problemas interpretativos, ya que exige una doble lectura que mezcla fundamentos retóricos y posibles referentes místicos. Más que simplemente regida por un principio de divisio textus, la obra impone al lector una forma de leer, ${ }^{6}$ razón por la cual es necesario el examen detallado de los setenarios dentro del Setenario.

Dejando de lado el aspecto simbólico, nos interesaremos por las modalidades de inclusión de dicha estructura en la trama general de la obra. Es posible identificar tres niveles de utilización de los setenarios. Primero, el nivel macroestructural, es decir la división general del Setenario en libros. Veremos que se relaciona en parte con el proceso compositivo de las Siete Partidas. Por otra parte, nos interesaremos por los setenarios intermediarios que unen las leyes entre sí, es decir, la concatenación o repartición de estas en conjuntos de siete. Por último, dentro de las leyes, examinaremos los elementos que contribuyen a formar los setenarios a partir de una agregación de argumentos que tienden a agotar la significación o precisar los matices de cada realidad evocada. Veremos que este nivel microscópico, sin duda el más fecundo, presenta límites y variaciones. 


\section{El NiVEL MACro: DE LA HERENCIA LEgAL A LA APROPIACIÓN SIMBÓLICA}

El primer nivel de estudio de los setenarios es el de la composición general de la obra. Para entender mejor la posible división del Setenario en siete partes, hay que remontarse al proceso de composición de las Siete Partidas, texto del que constituye una reescritura. La organización de las Partidas se conforma con el modelo del Digesto de Justiniano y de la Summa Azonis. El Digesto se compone de cincuenta libros repartidos en siete partes. Cada libro se subdivide en títulos, divididos a su vez en fragmentos correspondientes a cada uno de los juristas citados. La Summa Azonis, que es una glosa al Digesto, imita la forma del texto al que se adjuntó. Ambos textos parecen haber inspirado la estructuración general de las Siete Partidas, tanto al nivel de la organización por libros como de la triple subdivisión del texto. Sin embargo, el código legal de Alfonso $\mathrm{X}$ incluye una sistematización de la subdivisión en títulos, así como una innovación, ya que cada Partida empieza por una inicial del nombre "Alfonso", lo cual permite vincular directamente la suma jurídica con la autoridad real.

Tanto la organización general como el recurso al acróstico difieren en el Setenario. En efecto, encontramos a lo largo de la obra referencias a una división por libros (seis referencias) o partes (dos referencias). Solo cuatro de las ocho menciones tienen relación directa con la posible estructura del tratado tal como fue ideado. Dicha cuestión ha sido ya debatida. Para Gómez Redondo (1998-2007), el Setenario es un texto temprano, ideado por Fernando III a partir de un plan en siete partes. Esta hipótesis se basa en el contenido de la ley X en la que se afirma que el rey Fernando III: “(...) partió este libro en siete partes” (Alfonso X, ed. 1984, X, p. 25, 1. 14-15). En su opinión, al proseguir con la redacción del libro, Alfonso X dejó una obra bipartita. El proyecto fernandino correspondería así a las leyes XII a CVIII, y el alfonsí, a las leyes introductorias, o sea I a XI (Gómez Redondo, 1998-2007). Al no haberse concluido el Setenario, ningún elemento nos permite comprobar esta hipótesis. Por el contrario, Martin (2001) ha defendido la unicidad profunda del texto a pesar de las rupturas lógicas y semánticas provocadas por las lagunas. Asimismo, ha insistido en que la autoría efectiva de Fernando III es, sin duda alguna, una ficción literaria. ${ }^{7}$ La atribución del proyecto al padre de Alfonso X trata de legitimar el proyecto de escritura adscribiéndolo a la empresa intelectual impulsada por el Rey Santo, dotando a su contenido de una dimensión sagrada a la que remite constantemente la forma del Setenario. Herencia y genealogía del texto van unidas en una especie de escenificación del proyecto de escritura, escenificación que une la figura del padre y la del soberano en un mismo acróstico inicial (ley I). Sin duda hay que considerar esta atribución falaz, realizada con la voluntad de conformarse con el proyecto totalizador que persigue que todo elemento presente en la obra se incluya en un esquema rítmico idéntico y asimilado al número siete.

El acróstico que se extendía a cada una de las Siete Partidas ha sido completamente transformado en el Setenario. El procedimiento ha sido limitado a la primera ley, en la que cada letra del nombre del soberano, espejo de la fórmula "Alfa et O" y del nombre "Ferando", origina una enumeración de siete nombres divinos con su glosa. Esta amplificación sistemática, concebida a partir de fuentes e imaginarios múltiples (Puigdengolas, 2019), también es un programa compositivo. La compleja elaboración nominalista que hace de prólogo al Setenario, anticipa su contenido temático, puesto que la interpretación de nombres divinos, así como la ley XI, constituyen dos formulaciones distintas de una propedéutica temático-teórica cuyos ecos se encuentran a lo largo de la obra. Las reformulaciones y reiteraciones continuas del material introductorio se adecuan al marco formal y favorecen, por otra parte, la cohesión del discurso. Así, la presencia de la autoridad regia se hace más patente que en las versiones sucesivas de las Partidas, ya que ocupa tanto el umbral de la obra como la totalidad de su contenido. Al concentrar este procedimiento en la primera unidad textual, es la representación misma del poder real la que se ha cambiado. A partir de las leyes iniciales, se transfigura completamente la organización del modelo que eran las Partidas. El recurso sistemático a un procedimiento enumerativo, ajeno a la forma inicial de la escritura legal regia, así como el espesor simbólico renovado de la 
figura del monarca, rompen con la tradición romana del ius dicere. Con el Setenario, Alfonso X se apropia plenamente de la escritura jurídica.

\section{EL NIVEL INTERMEDIO: ¿UNA REDACCIÓN POR SEGMENTOS?}

Es posible distinguir varios movimientos setenarios dentro del plan general de la obra. Este nivel intermedio, situado entre la organización macroscópica de la obra y el nivel microscópico que representaría el contenido de las leyes, puede dividirse en dos tipos de manifestaciones: por un lado, este nivel concierne el agrupamiento o la repartición de leyes según su contenido temático; por otra parte, concierne la concatenación de las leyes entre sí mediante fórmulas retóricas.

De forma analógica, cada vez que una realidad concreta se declina según siete realidades, encontramos un setenario. Esto se produce en tres ocasiones: cuando se trata de los fenómenos visuales (leyes XII a XVII), de los planetas ${ }^{8}$ (leyes XXV a XXXII) y de la correspondencia de los astros con los misterios del cristianismo (leyes XLVIII a LIV). Si bien las dos últimas series se justifican por tener como referente la realidad física concreta que son los siete planetas, ${ }^{9}$ es probable que el primer conjunto se haya concebido a partir de una fuente. En efecto, las leyes XII a XVII presentan los sueños y otros fenómenos ópticos (ssecta, opinión, antoiança, ffantasía, suenno, visión). Definen un contraprograma noético en la medida en que cada fenómeno descrito es una forma errónea de creer o percibir. En ello, se oponen a las premisas enunciadas en las leyes I y XI. La lista se inspira sin duda en la tipología de los sueños incluida en el Comentario al sueño de Escipión de Macrobio (I, 3), como ha sugerido Perona (1988), así como en algunas leyes de las Siete Partidas. ${ }^{10}$ Este tipo de organización temática propicia, en la trama de la obra, la aparición de grupos de capítulos. Sin embargo, entre las ciento ocho leyes que componen el Setenario, solo veintiuna se agrupan en bloques de siete. Estos conjuntos, aislados en la obra, no tienen valor de norma estructural. A pesar de su escasez, la existencia de estos bloques evidencia la preocupación de los redactores de conformarse en todo momento con el proyecto de escritura definido desde las primeras líneas.

Aunque sea objeto de conjeturas, podríamos aplicar este análisis a las diez primeras leyes del Setenario. En efecto, las unidades semánticas correspondientes a las leyes I a IV y VI de la edición de Vanderford se caracterizan, en el manuscrito conservado en Toledo (ms. 43-20), por la ausencia de titulación o de una frase que resuma su contenido. Al observar este manuscrito, parece que este conjunto inicial consta de siete leyes, ya que las leyes I a IV constituyen una única unidad formal, las leyes V y VI un segundo bloque, y las cinco leyes siguientes (VII a XI) que llevan un título, las demás unidades de este setenario inaugural. Esta división tiene correspondencia exacta con la estructura de una copia del siglo XVIII (ms. 26-14) destruida durante el incendio de la biblioteca de Jovellanos en Gijón el 21 de agosto de 1936, pero de la que conservamos una recensión detallada (Somoza, 1883). Se trataba de un collage de varios fragmentos provenientes de las leyes II a X, cuyo orden y contenido se modificó para centrarse en la descripción de Sevilla ${ }^{11}$ y conformarse, por otra parte, con la arquitectura general reivindicada por los redactores alfonsíes. La pérdida del testimonio gijonés, así como las dudas que persisten acerca de la verdadera extensión de los elementos que preceden a la ley XI, no nos permiten ahondar en el estudio de la organización de las leyes introductorias.

Intentos de organización semejantes pueden percibirse en el contenido de la obra. Es el caso del final de la ley LXXVI, que esboza un verdadero plan redaccional, ya que anuncia los puntos que serán detallados en las leyes siguientes. Así, prevé una explicación en siete etapas de las especificidades del sacramento del bautismo:

(...) la primera, quál es en ssí; la ssegunda, cómmo ffué establecido e quándo; la tercera, quántas maneras sson del; la quarta, a quántas cosas tiene pro; la quinta, quién le puede ffazer; la ssesta, cómmo deue sser ffecho; la sséptima, cómmo deue sser onrrado e guardado. (Alfonso X, ed. 1984, LXXVI, p. 128, 1. 8-13)

Si volvemos al contenido de la obra, constatamos que se añadieron varios elementos a este plan inicial. La ley LXXVII corresponde al primer punto anunciado, la ley LXXVIII al segundo y las leyes LXXIX a 
LXXXI al tercero. Se introduce así una primera tripartición que precisa las palabras que han de pronunciarse durante el rito, que condena algunas prácticas y que prescribe otras en cuanto a las maneras de bautizar. El cuarto punto corresponde a la ley LXXXII, el quinto a la LXXXIII. El sexto punto está subdividido en tres leyes (LXXXIV a LXXXVI) que detallan los ritos precisos que han de ejecutarse antes, durante y después de la celebración del bautismo. El último elemento se desarrolla en la ley LXXXVII. En total, para la presentación de este sacramento y a pesar del plan establecido, son once leyes las que conforman la sección temática dedicada al bautismo, ya que dos aspectos se han especificado en conjuntos de tres leyes. Esta amplificación formal del proyecto inicial, plan respetado a la perfección desde un punto de vista estrictamente temático, provoca una dilatación en la trama general y para el receptor, sea leyente u oyente. Este desequilibrio relativo puede considerarse como la señal de una evolución del proyecto redaccional del Setenario y, muy probablemente, de una redacción por fragmentos en la que intervinieron varios autores. ${ }^{12}$

La búsqueda de setenarios por medio de conexiones retóricas parece tan poco concluyente como la de bloques temáticos. Un único caso de vinculación se encuentra en la obra. Se trata de las leyes XXVI a XXXII, que remiten anafóricamente y de forma sistemática al último párrafo de la ley $\mathrm{XXV}$, en el que se enumeran los elementos naturales en los que influye el andar de los astros:

Et por esta nobleza e vertud que auyan en ssí, dixieron que auyan poder ssobre ssiete cosas, assí commo ssobre los elementos, et ssobre las animalias, e ssobre las plantas, e ssobre las mineras, e ssobre los tienpos, e ssobre las edades, e ssobre las vidas. Et ssegunt las obras que ffazíen en cada una destas cosas, pusiéronles assí nonbre. (Alfonso X, ed. 1984, XXV, p. 57, 1. 25-30)

Según se afirma, todos los planetas comparten dichas características. De hecho, al final de cada ley que los presenta, encontramos un sintagma que remite a la estructura modélica enunciada en la ley inicial de la serie:

\footnotetext{
Et dáuanle otrossí parte con las otras planetas en aquellas ssiete cosas que de ssuso son dichas en la ley ante désta. (Alfonso X, ed. 1984, XXVI, p. 58, 1. 22-24)

Et dizían otrossí que auya parte con las otras planetas en aquellas ssiete cosas que de ssuso sson dichas en la ssegunda ley ante désta. (Alfonso X, ed. 1984, XXVII, p. 59, 1. 11-13)

Et dauánle parte otrossí en las ssiete cosas que de ssuso sson dichas en la terçera ley ante désta. (Alfonso X, ed. 1984, XXVIII, p. 59, 1.29-30)

Et dauánle otrossí parte más ffirmemientre que a las otras planetas en las ssiete cosas que sson dichas e n la ley quarta ante désta. (Alfonso X, ed. 1984, XXIX, p. 60, 1. 18-20)

(...) e dauánle otrossí parte con las otras planetas ssegunt de ssuso es dicho en la quinta ley ante désta. (Alfonso X, ed. 1984, XXX, p. 62, 1. 4-5)

Et dauánle otrossí parte en las ssiete cosas que sson dichas en la ley ssesta ante désta. (Alfonso X, ed. 1984, XXXI, p. 62, 1. 22-23)
}

Las leyes XXV a XXXI mezclan afinidades temáticas y concatenación retórica. De este modo, combinan dos usos distintos del setenario. Por otra parte, constituyen el único setenario de índole estilística de la obra. Hay que entender esta excepción como la voluntad de aplicar el procedimiento a unidades de diferente índole. Mediante este juego de referencias, los redactores del Setenario lograron forjar una cadena argumentativa cuyo hilo conductor es el setenario, erigido en denominador formal y semántico. Con ello, rompieron con un uso estrictamente limitado al contenido de las leyes, tal como sugirió Baldissera: "Creare una catena argomentativa superiore al blocco delle concettuale costituito dalla singola ley” (1996, p. 143).

Sean formales o temáticos, programáticos o ilativos, los intentos de crear setenarios destinados a unir diferentes unidades textuales entre sí no fueron más que experimentos en el proceso genético del Setenario. Es probable que, de terminarse la obra, hubiesen adquirido más impacto en la trama. Al ser un cuaderno de trabajo, un borrador inacabado ideado a partir de un imaginario numérico aplicado a un material tan heterogéneo y abundante, la obra nos permite examinar, a la manera de un boceto, los tanteos y las vacilaciones de sus redactores. Estos intentaron aplicar el procedimiento estilístico en varios planos y según principios múltiples, lo cual confiere a la ffabla un espesor que cada lectura ayuda a descifrar. 


\section{EL NIVEL MICROSCÓPICO: LÓGICA Y REESCRITURA}

El nivel microscópico es el más fecundo para observar los setenarios. Sin embargo, su estudio es bastante arduo por corresponder a realidades dispares tanto desde el punto de vista cualitativo como cuantitativo. En su trabajo sobre el imaginario del siete en el Setenario, Perona (1988) había identificado ciento cuatro setenarios. Un examen más detallado revela que dichas estructuras son ciento cuarenta y dos a lo largo de la obra. La diferencia de total se explica por el hecho de que Perona se ha centrado en los setenarios que designaremos como principales, es decir, aquellos que se desglosan en las consideraciones liminares de cada ley. En cambio, no prestó atención a los setenarios conclusivos, a los ilativos ni a los setenarios secundarios que se extienden en las leyes bajo la forma de ramificaciones, de glosas o de digresiones.

En la mayor parte de los capítulos, los setenarios han sido compuestos por una absorción y reorganización de unidades semánticas (a menudo leyes enteras) sacadas de las Siete Partidas. ${ }^{13}$ Funcionan por pares dentro de un esquema redaccional que hace pensar en la estructura de la lectio medieval. En efecto, en muchas leyes encontramos primero una divisio que sirve de sumario y detalla siete aspectos inherentes a un tema particular enunciado en el título de la ley. Luego, una expositio reitera, detallándolos, cada uno de los puntos pormenorizados en la introducción para examinar sus implicaciones concretas. Por fin, una explicatio concluye el análisis y lo relaciona con la argumentación general del tratado. Para las leyes I a XI, el fenómeno de reduplicación del setenario es tanto más marcado cuanto que treinta y siete de los cuarenta y cuatro setenarios que contienen se han puesto de relieve, en los manuscritos, mediante dibujos ovalados que encierran y aíslan cada uno de los términos que los componen. La existencia de este proceso reiterativo nos invita a pensar que la obra podía consultarse de dos maneras: o bien de forma íntegra, leyendo la totalidad de cada ley, o bien limitándose a los setenarios que las inauguran, señalizados con estos óvalos tan característicos. Según Baldissera (1996), las subdivisiones setenarias parecen incluirse y adaptarse a un esquema redaccional en cinco partes definido en la Rhetorica ad Herennium.

Desde un punto de vista cualitativo, los setenarios pueden repartirse en cuatro categorías. La primera categoría está formada por términos glosados. Se trata de un fenómeno limitado principalmente a la ley I, dedicada al acróstico a partir de nombres divinos en latín, griego y hebreo. En esta ley, son los mismísimos nombres divinos los elementos constitutivos de los setenarios. La mayor parte de dichas explicaciones son de índole etimológica o simbólica. Provienen de índices de nombres bíblicos que eran familiares a los redactores alfonsíes (Puigdengolas, 2019). Se trata de la forma más sencilla, aunque analítica. Los setenarios presentes en esta ley inicial son los únicos en integrar los tres idiomas sagrados.

El resto de los setenarios fueron compuestos a partir de unidades semánticas destinadas a explicitar un tema particular. El segundo tipo de setenarios que se incluye en esta categoría fue elaborado a partir de polisíndeton compuestos de conjunciones copulativas:

Mas porque la crisma es vnto ssanto con que sse deue ffazer el baptismo, queremos dezir primeramiente qué cosa es en ssí la crisma e quién la puede ffazer; et de qué cosas ha de sser flecha; e en qué tienpo e en qué logar; e en qué manera deuen tener apareiadas las cosas para ffazer la crisma; et de cómmo la deuen adozir los clérigos al altar para ssagrarla; [et de cómmo deuen boluer el olio de la crisma con del olio del bálssamo]; et en qué guisa deue sser benedito e sagrado el olio para los cathecúminos e neóffitos e aducho al ssagrario onrradamiente. (Alfonso X, ed. 1984, LXXXVIII, pp. 153-154, 1. 26-31 y 1-3)

Estos no van necesariamente precedidos por un sumario, sino directamente insertados en una ley sin haberse identificado como el elemento temático dominante. Muchos ejemplos de este tipo pueden apuntarse dentro de la ley XI, designada en consecuencia por el texto mismo como "ssetenario mayor" (Alfonso X, ed. 1984, XI, p. 46, 1.4).

Las listas también pueden adoptar la forma de una sucesión de subordinadas, lo cual constituye una tercera modalidad de inclusión en la obra: 
E éste ha en sy siete cosas: la primera es seer, ca él fué sienpre e es e será; que es todo spíritu noble e conplido, donde nacen todos los otros; que es tan claro que ninguna cosa non le puede veer; que es linpiedunbre conplida, en que ninguna cosa non puede prender nin allegarse a él que sea suzia; que es todo bueno en sy e fas sienpre bien; que es en todo e non ha lugar sennalado; que non puede ser medido nin cabopreso por fecho nin por forma. (Alfonso X, ed. 1984, XXXV, pp. 66-67, 1 . $35-37$ y $1-5)$.

La última modalidad es una combinación de las dos anteriores, ya que articula polisíndeton y subordinadas dentro de enumeraciones complejas. Se trata generalmente de setenarios principales que contienen la totalidad del propósito y que constituyen un resumen del contenido de cada ley o conjunto de leyes.

A pesar de la presencia de estos programas redaccionales, percibimos algunas digresiones o desviaciones. La ley LXIII, por ejemplo, tiene como objetivo examinar los parecidos entre el signo del Sagitario y la figura de Cristo a partir de siete razones:

(...) la primera, por la ilación que ha en ssí de omne; la iia de cauallo; la tercera, que tiene arco con cuerda; la quarta, porque tira saetas; la quinta es porque el su tirar es sienpre adelante, e non atrás; la ssesta es porque tiene toca en la cabeça, puesta sobre los oios; la viia, porque es tan grande que tiene el pie delantero metido entre él e la cuerda. (Alfonso X, ed. 1984, LXIII, p. 105, 1. 5-11)

Sin embargo, el segundo punto de este plan inicial nunca aparece en la ley. En vez de examinar el cauallo, el texto trata del especial entendimiento de esta figura doble capaz de percibir la divinidad:

La iia, ffué muy ffuerte de ascuchar e de oyr e más graue de uer por vista, en dezir que Dios e omne es vna cosa. Et esto non podríe caber en natura de entendimiento fflaco que es vsado al mundo; mas cabe en entendimiento bueno e ffuerte de la natura de Dios, de ssaber connosçer con qué ffizo e puede ffazer quanto quisiere ssin enbargo ninguno. (Alfonso X, ed. 1984, LXIII, p. 105, 1. 16-21)

Esta modificación evidencia de nuevo la constante evolución del texto. Es posible que introducción y contenido de la ley sean el fruto de escribas distintos, o bien simplemente que el redactor de la ley haya decidido modificar su tenor a medida que iba componiendo.

El comentario de los setenarios principales puede ser muy complejo por integrar varias ramificaciones. La estructura de la ley CIV es ejemplar al respecto (véase Anexo). En esta ley se examina la preeminencia del sacramento de la comunión a partir de la imbricación de varias enumeraciones, entre las cuales se encuentran dos setenarios. La compleja organización formal de esta pieza argumentativa dificulta la comprensión. Si volvemos al andamiaje teórico que propone, encontramos en primer lugar la presentación de los componentes del setenario principal:

E por ende conviene agora que se diga de estas siete rrazones: la primera, qué cosa es comunión e por qué asy ha nonbre; la iia, quién la establesció; la iiia, de qué cosas se faze; la iiiia, en qué manera deue ser fecha; la va, quién lapuede fazer; la via, a qué tiene pro; [la viia], cómmo deue ser honrrado e guardado. (Alfonso X, ed. 1984, CIV, p. 231, 1. 6-11)

El primer punto origina una glosa de índole etimológico-lexicográfica que se divide en tres ramas dedicadas a cada una de las "noblezas" del sacramento. El segundo aspecto no incluye digresiones. El tercer argumento se subdivide primero en tres puntos correspondientes a las maneras de consagrar el cuerpo de Cristo: el pan, el agua y el vino. El examen del pan lleva a otra subdivisión ternaria. Luego, se vuelven a enumerar tres elementos para evocar: “(...) tres maneras de omnes que sse ayuntaron a matarle [Cristo]" (Alfonso X, ed. 1984, CIV, p. 233, 1. 6-11). Mientras se vuelve a hablar de las especies de la misa, tropezamos con el elemento estructural más problemático de la ley. El párrafo empieza por la fórmula "La tercera cosa (...)" (Alfonso X, ed. 1984, CIV, p. 234, 1. 23), lo cual enturbia la lectura ya enrevesada del setenario principal cuyo tercer argumento ha sido expuesto con anterioridad. Se trata en realidad de una tercera digresión ternaria, derivada del tercer argumento del setenario principal, lo cual no ha de confundirse con ese tercer argumento. Antes de que se exponga el cuarto argumento del setenario principal, otra digresión ternaria trata de los tres martirios de Cristo. Llegamos después al cuarto argumento que incluye en su desarrollo el segundo setenario de la ley, dedicado a las oraciones y a su comentario. En la edición de Vanderford, el pasaje está entrecortado 
por sangrados que segmentan la lectura y complican la delimitación de ambos setenarios. Los tres últimos elementos del setenario principal no incluyen digresiones, con lo cual termina la ley sin más precisiones ni posible confusión con los tres últimos argumentos del segundo setenario de la ley, argumentos que van inmediatamente antes.

La ley CIV nos lleva a afrontar los límites del setenario en tanto que estructura semántica. Aun si permite combinaciones múltiples, parece obvio, a la luz de lo expuesto, que este no basta para exponer la totalidad de las ideas asociadas a cada temática incluida en el Setenario. Los redactores recurren de hecho a variaciones y ramificaciones, e insertan más enumeraciones en las enumeraciones. Así, los setenarios pueden presentarse bajo la forma de arborescencias, es decir, que todo o parte de sus elementos constitutivos se subdividen en otros siete elementos. Es el caso de las leyes I, IX, X, XI, XXXIX, XL y LXXIII (Baldissera, 1996). Además, veinte leyes están desprovistas de setenarios a nivel microscópico: leyes XII a XVIII, XXIV, XXVI a XXXIV, XXXVI y LXVIII. Estos capítulos comparten otras características notables: su contenido no proviene de las Siete Partidas; cuando están aislados, son a menudo piezas de transición entre el material proveniente de las Partidas y el material creado por los redactores a partir de la selección y compilación de otras fuentes; cuando se agrupan, constituyen unidades temáticas a escala de la obra.

El setenario no es el único condicionante formal de la obra. Si cuantitativamente constituye el procedimiento estilístico más representado, está articulado mediante otras estructuras que afectan el texto a niveles variables. La primera de ellas son las series ternarias. Estas enumeraciones mínimas se implantan a menudo en conjuntos más amplios, siendo partes de setenarios o derivadas de ellos. Por ejemplo, las referencias a la Trinidad son especialmente idóneas para la composición de setenarios, ya que al conjunto de las hipóstasis se suele añadir cuatro elementos que permiten formar series de siete realidades similares. Encontramos así, al lado de las figuras trinitarias, los Evangelistas, las virtudes cardinales o bien las bestias que rodean al trono divino.

Otro denominador formal, concebido como una extensión del setenario, es la división duodecimal. La justificación de su presencia está ausente del Setenario. En cambio, la glosa insertada por Gregorio López al lado del término "Septenario", que hace de segundo prólogo en la edición de las Siete Partidas de 1555, remite a una posible fuente de esta prolongación estructural. Se trata del capítulo 7 del libro 35 de las Moralia in Iob de Gregorio Magno. En el fragmento citado por López, encontramos la explicación de las relaciones que unen el número siete al doce, según se añaden o se multiplican, tres y cuatro:

Septenarius autem numerus apud sapientem hujus sæculi quadam sua habetur ratione perfectu, quod ex primo pari et ex primo impari consummatur. Primus enim impar ternarius est, primusque par quaternarius. Ex quibus duobus septenarius constat, qui eisdem partibus suis multiplicatus in duodenarium surgit. Nam sive tres per quatuor, seu quatuor per tres ducimus, ad duodenarium pervenimus. (Grégoire le Grand, Moralia in Job, PL, pp. 757-758)

Los colaboradores de Alfonso X conocían este texto que había integrado muchas bibliotecas de la Península. Sin duda se inspiraron en la especulación aritmética de Gregorio Magno a la hora de concebir el Setenario. Recordemos que los Moralia constituyen el best-seller de la Edad Media, con cerca de mil quinientos manuscritos diseminados por toda Europa (Siri, 2018). Para el espacio correspondiente a la antigua extensión de los reinos ibéricos, Silva y Verástegui (1996), que completa la lista inicial propuesta por Díaz y Díaz (1991), ha identificado un total de veintisiete manuscritos que aún se conservan.

En cuanto al contenido del Setenario, la complementariedad de ambos números permite introducir variaciones a partir de esquemas repetitivos, así como un juego de correspondencias entre las temáticas abordadas. Por un fenómeno de contraposición, contribuye a oponer lo verdadero y lo virtuoso a lo erróneo y al pecado:

(...) assí commo estos doze signos muestran la uerdat de las vii planetas, assí los xii apóstoles muestran la uertud de los vii sacramentos de Ihesu Cristo, que ffueron puestos e ordenados en Santa Eglesia contra los vii peccados que los omnes fazen (...) (Alfonso X, ed. 1984, LXVI, p. 113, 1. 3-7) 
Esta extensión formal se aprehende, al igual que el setenario mismo, como un formato de índole analógica. En el Setenario hay estructuras duodecimales porque, de la misma manera que en el Libro del Apocalipsis, el tema del que se trata es un conjunto de doce realidades:

(...) ouo de ffazer libro, que llaman Apocalipsi, que quier dezir en griego visiones marauillosas de los secretos de Dios. E este libro es partido por cuento de siete e de doze, en que mostró el cuento derecho de las siete planetas uerdaderas e de los doze signos. (Alfonso X, ed. 1984, LXVII, p. 113, 1. 22-26)

En el Setenario, el procedimiento se limita a dos temas: los signos astrológicos y los apóstoles. La subdivisión afecta también a los capítulos anexos a estas temáticas generales. Pensemos, por ejemplo, en la descomposición de la oración del Credo en la ley XLII (Alfonso X, ed. 1984, XLIII, p. 73, 1. 5-24).

La recurrencia del esquema setenario es incuestionable. Es el resultado del cruce entre varias tradiciones intelectuales que encontraron eco en la producción alfonsí y, más precisamente, en el Setenario. Si Alfonso $\mathrm{X}$ se inspira en modelos preexistentes para dar forma a sus listas, inventa el contenido de la mayor parte de ellas. ${ }^{14}$ Recurre al número siete tanto para la divisio como para la compositio. Lo usa para separar cada idea, ponerla de relieve dentro de una serie, pero constituye también el denominador gracias al cual se unen los elementos que componen cada serie de temática común. Se caracteriza por su adaptabilidad, su capacidad de integración y la originalidad de las combinaciones que permite. Su aplicación en la obra es irregular. Al estudiar sus diversas manifestaciones, adivinamos la voluntad de extender su uso a todos los planos de este texto en construcción.

\section{ConCLUSIón}

El setenario y sus variantes afectan a todos los niveles de la composición del Setenario. Nos permite reconectar con el sentido de esta obra inacabada a partir de un triple foco. Al examinarlos detenidamente, se percibe que los setenarios son contexturas maleables de las que se ha querido explotar las posibilidades y la extraordinaria polisemia. Son reveladores del proceso genético de la obra y constituyen un método de segmentación visual y auditivo que ayuda al lector a leer. El carácter reiterativo de la estructura confiere cierta circularidad al discurso. Todo vuelve a repetirse en una especie de letanía en la que fondo y forma se contemplan en una relación lógica y, a menudo, analógica. El setenario contribuye así a una búsqueda continua de sentido gracias a una peculiar codificación. Sin embargo, este criterio tiene sus límites porque no permite organizar la totalidad de las informaciones relativas a cada tema, porque no se adecua simbólicamente a todos los conjuntos y porque supone un esfuerzo mnemotécnico: "One can have three or five or seven images in a single group but not many more, because one tends to lose track over seven” (Carruthers, 1990, p. 167). Así, paradójicamente, este procedimiento representa tanto un esfuerzo para ordenar como un factor de confusión que ha desorientado a muchos de sus lectores modernos. ${ }^{15}$

Con todo, no se puede reducir el estudio de la estructura del Setenario a una mera investigación del "setenarismo" (Perona, 1998) ni de sus expresiones en la obra, sino al desglose de todos los elementos y procedimientos textuales que hacen posible al lector abordar el discurso y su lógica. Esta es, precisamente, nuestra propuesta de trabajo. Para entender mejor las diferentes articulaciones del enunciado, conviene reestudiarlo en su progresión. Este análisis extensivo permitirá detectar parte de las rupturas formales y semánticas, así como circunscribir segmentos específicos susceptibles de haber sido redactados por manos diferentes o, por lo menos, concebidos según principios redaccionales divergentes. Al salir de lo estrictamente formal, proponemos un foco en la complementariedad entre trama formular y trama narrativa. En ese sentido, nuestra propuesta metodológica conlleva la identificación de las conexiones discursivas propias del Setenario por medio del cotejo con las de los estadios redaccionales anteriores. Por último, a partir de la reciente sugerencia de Rodríguez-Velasco (2020), propondremos abordar el Setenario como un mapa conceptual-verbal. Esto implica prestar atención al doble régimen de lectura ya mencionado y que puede 
conducirse a través de los óvalos presentes en los manuscritos de las primeras once leyes. Todos estos elementos permiten demostrar que, además de ser un casum unicum dentro del corpus alfonsí (FernándezOrdóñez, 2010), el Setenario también propone modalidades de consulta inéditas que se revelan por su especial organización microscópica.

\section{ReFERENCIAS}

Baldissera, A. (1996). Retorica nel Setenario di Alfonso X el Sabio. Il confronto letterario, XIII(25), 137-158.

Burriel, A. M. (1800). Memorias para la vida del Santo Rey Don Fernando III dadas á luz con apéndices y otras ilustraciones por Don Miguel de Manuel Rodríguez. Madrid: Imprenta de la viuda de don Joaquín Ibarra.

Carruthers, M. (1990). The Book of Memory. A study of Memory in Medieval Culture. Cambridge: Cambridge University Press.

Craddock, J. R. (1986). El Setenario: última e inconclusa refundición alfonsina de la Primera partida. Anuario de Historia del Derecho Español, 56, 441-446 (recogido en J. R. Craddock (2008). Palabra del rey: selección de estudios sobre legislación Alfonsina. Salamanca: Semyr).

Díaz y Díaz, M. C. (1991). Libros y librerías en la Rioja altomedieval. Logroño: Diputación Provincial de Logroño.

Eco, U. (1979). Lector in fabula. Paris: Flammarion.

Eco, U. (2009). Vertige de la liste. Paris: Flammarion.

Fernández-Ordóñez, I. (2010). Ordinatio y compilatio en la prosa de Alfonso X el Sabio. En M. Castillo Lluch y M. López Izquierdo (Eds.), Modelos latinos en la Castilla medieval (pp. 239-270). Madrid / Frankfurt am Main: Iberoamericana / Vervuert.

Flores Arroyuelo, F. J. (1985). El 'Setenario', una primera versión de los capítulos introductorios de 'Las Siete Partidas'. En F. Carmona y F. J. Flores (Eds.), La lengua y la literatura en tiempos de Alfonso X: Actas del Congreso Internacional, Murcia, 5-10 marzo 1984 (pp. 169-179). Murcia: Universidad de Murcia.

Genette, G. (1987). Seuils. Paris: Seuil.

Gómez Redondo, F. (1998-2007). Historia de la prosa medieval castellana (vols 1-4).Madrid: Cátedra.

Grégoire le Grand. Moralia in Job. Ed. Migne, Jacques-Paul (1815-1875). Patrologia Latina (vols. 75-76).

Gutwirth, E. (2005). Temas setenarios. Estudios mirandeses, 25, 80-93.

Martin, G. (1993). Alphonse X ou la science politique (Septénaire, 1-11). Cabiers de Linguistique Hispanique Médiévale, 18-19, 79-100.

Martin, G. (1995). Alphonse X ou la science politique (Septénaire, 1-11). Cabiers de Linguistique Hispanique Médiévale, 20, 7-33.

Martin, G. (2001). Datation du Septénaire : rappels et nouvelles considérations. Cabiers de Linguistique et de Civilisation Hispaniques Médiévales, 24, 325-342.

Martin, G. (2 de diciembre de 2006). De nuevo sobre la fecha del Setenario. e-Spania. Recuperado de http://journal s.openedition.org/e-spania/381

Martínez, H. S. (2016). El humanismo medieval y Alfonso Xel Sabio. Ensayo sobre los orígenes del humanismo vernáculo. Madrid: Ediciones Polífemo.

Panateri, D. (4 de abril de 2018). Sapiencialismo y legalismo, una distinción útil para Las Siete Partidas. 7PartidasDigital. Edición critica digital de las "Siete Partidas". Recuperado de https://7partidas.hypotheses.org $/ 1170$

Pérez López, L. (2002). Los prólogos del Libro de las leyes y el fragmento llamado Setenario en la obra jurídica alfonsí. Revista de literatura medieval, 14(1), 109-143.

Perona, J. (1988). Espesores simbólicos de la glosa del mundo: el Setenario alfonsí, una aritmología sagrada. Glossae: revista de historia del derecho europeo, 1, 35-96. 
Perona, J. (1998). La obra enciclopédica de Alfonso X. En E. Ramón Trives y H. Provencio Garrigós (Eds.), Estudios de lingüística textual: homenaje al profesor Muñoz Cortés (pp. 345-357). Murcia: Editum, Ediciones de la Universidad de Murcia.

Petrucci, A. (1984). Lire au Moyen Âge. Mélanges de l'École française de Rome. Moyen-Âge, Temps modernes, 96(2), 603-616.

Puigdengolas, J. (2019). Passer le pouvoir: Modalités de réécriture dans le Setenario d'Alphonse X. En V. LamazouDuplan (Dir.), Écritures du pouvoir. Les cultures politiques dans la Péninsule Ibérique et au Maghreb (VIIIèmeXVìme siècle), 2 (pp. 73-85), Bordeaux: Éditions Ausonius.

Real Academia de la Historia (1807). Las Siete Partidas del rey don Alfonso el Sabio, cotejadas con varios códices antiguos por la Real Academia de la Historia. Madrid: Imprenta real.

Rodríguez-Velasco, J. (2020). Dead Voice. Law, Philosophy and Fiction in the Iberian Middle Ages. Philadelphia: University of Pennsylvania Press.

Ruiz García, E. (2006). Rex scribens: Discursos de la conflictividad en Castilla (1230-1350). En J. M. Nieto Soria (Dir.), La monarquia como conflicto en la Corona castellano-leonesa (1230-1504) (pp. 359-422). Madrid: Sílex Ediciones.

Silva y Verástegui, S. de (1996). Un nuevo ejemplar ilustrado de los Morales de Gregorio Magno (B.A.H Cod. 1) del siglo XIII, inédito. Archivo Español de Arte, LXIX(276), 407-421.

Siri, F. (marzo de 2018). Les best-sellers du Moyen Âge. L'Histoire. Recuperado de http://www.lhistoire.fr/irht-dansle-secret-des-manuscrits/les-best-sellers-du-moyen-age

Somoza de Montsoriu, J. (1883). Catálogo de manuscritos e impresos notables del Instituto de Jovellanos en Gijón, seguido de un indice de otros documentos inéditos de su ilustre fundador. Oviedo: Vicente Brid.

Vanderford, K. H. (Ed.). Alfonso X el Sabio (1984). Setenario. Barcelona: Crítica.

\section{Anexo : estructura de la ley CIV}

En el presente anexo se detalla la estructura de la ley CIV. Se han indicado siempre los calderones presentes en el manuscrito 43-20 (פ), que permiten delimitar las unidades semánticas y facilitar visualmente la lectura.

I, La primera, qué cosa es en sy [e] por qué ansy ha nonbre.

I. 1. (...) ha tres noblezas (...)

I. 1. 1. (...) la primera, porque es fecho el cuerpo de Nuestro Sennor Ihesu Cristo Dios verdadero;

I. 1. 2. (...) la iia, que mostró que los sacrificios eran fechos por toller cada vno su pecado, e éste para tollerlos todos;

I. 1. 3. (...) la iiia, porque éste sacrificio es que se da a entender que Nuestro Sennor Dios non nos oluida nin se parte de nos synon quando viene por nuestra grant culpa.

g II, [La] segunda, [quién la establesçió].

III, La tercera, de qué cosas sse ffaze.

III. 1 estas tres cosas:

III. 1. 1. pan;

III. 1. 1. 1. La primera, por el nonbre dél (...)

III 1. 1. 2. La ssegunda rrazón es porque el ffructo (...)

III. 1. 1.3. a tercera, porque el pan, (...) 
III. 1.2. e vino;

III. 1. 3. e agua.

III. 2. (...) ca tres maneras de omnes (...)

III. 2. 1. La vna, el pueblo (...)

III. 2. 2. La ssegunda manera de omnes, que ffueron de judíos (...)

III. 2. 3. La tercera manera de omnes ffueron los rromanos (...)

III. 3. Onde destas tres guisas (...)

III. 3. 1. pan

III. 3. 2. 9 vino

III. 3. 3. La tercera cosa con que deuen ssacrifficar es el agua (...)

III. 4. [...] tres maneras de muy grant martirio (...)

III. 4. 1. (...) la primera, que la ssu [carne] ffué fferida e rronpida de muchas maneras;

III. 4. 2. (...) la ssegunda, que la ssu ssangre ffué esparzida por muchas partes;

III. 4. 3. (...) la tercera, porque ssalió el agua con ella (...)

IV, La quarta, en qué manera deue sser ffecho.

IV. 1. 1. La primera, que luego en el comienço rruega el preste a Dios Padre (...)

IV. 1. 2. I La segunda, cómmo se ffaze el pan carne (...)

IV. 1. 3. I La tercera, cómmo sse ffaze el vino ssangre.

IV. 1. 4. La quarta, cómmo ha de ffazer los ssignos de la cruz sobre la hostía e ssobre el cálice (...)

IV. 1. 5. La quinta, en cómmo rruega por los deffuntos e por los biuos.

IV. 1. 6. La ssesta es que pida a Dios que les libre de todo mal e les dé paz.

IV. 1. 7. La ssetena, el rreçibimiento del cuerpo de Nuestro Ssennor Ihesu Cristo rrenunçia el cuerpo del omne.

V V La quinta, quién lo puede ffazer.

VI, La ssesta, a qué tiene pro quando es la comunión rreçebida linpiamientre e con grant deuoçión.

VII, La ssetena, cómmo deue sser onrrado e guardado.

\section{Notas}

1. Nos referimos al debate existente entre defensores de una datación temprana de la obra (Vanderford, 1984; Flores Arroyuelo, 1985; Gómez Redondo, 1998-2007; Pérez López, 2002 y Salvador Martínez, 2016) y estudiosos que han demostrado, por el contrario, el carácter tardío de su composición (Craddock, 2008; Martin, 1993, 1995, 2001 y 2006).

2. Las lagunas del códice T (ms. 43-20, Archivo Capitular de Toledo) constituyen sin duda una transformación deliberada, ya que desaparecieron varios segmentos cuyo contenido tiene que ver con la evolución sapiencialista del texto. Al contrario, se ha conservado en el ejemplar T un texto más cercano a la tradición legalista de las versiones sucesivas de la Primera partida. Sobre los conceptos de sapiencialismo y legalismo en la producción jurídica alfonsí, puede consultarse Panateri (2018).

3. Nos referimos aquí a la postura crítica del lector moderno. Varias formulaciones diseminadas en el Setenario sugieren que la obra se destinaba tanto a un auditorio como a lectores: "ssegunt de ssuso es dicho", "que auemos dicho", "ya oystes de ssuso", "commo auedes oydo". Lo visual y lo auditivo eran tan fundamentales el uno como el otro en el proceso de lectura medieval (Petrucci, 1984). De hecho, las remisiones presentes en el Setenario tienen que ver con la mnemotecnia (Carruthers, 1990) y la percepción concreta del texto, fuese leído colectiva o individualmente, pero en voz alta. 
4. La cita no corresponde exactamente al texto de la edición de Vanderford, ya que este incluyó en su transcripción una nota marginal del ms. 43-20 que añadía a la justificación del título la palabra "Septenario": “(...) pusiémosle nonbre Septenario (...)".

5. El único elemento teórico relativo al número siete es su calificación como cuento: “(...) más noble que todos los otros (...)” (Alfonso X, ed. 1984, XI, p. 25, 1. 25).

6. En ello, el Setenario se adecua perfectamente al propósito de Umberto Eco en su ensayo. Recordemos que en la introducción a la edición francesa, el autor definía el doble papel de la lectura: "Il est très important d'étudier comment un texte est produit et comment toute lecture de ce texte ne doit pas être autre chose que la mise au clair du processus de génération de sa structure. J'en suis persuadé. Mais je pense qu'il est tout aussi important d'étudier comment le texte (une fois produit) est lu et comment toute description de la structure du texte doit être, en même temps, la description des mouvements de lecture qu'il impose" (1979, p. 8).

7. Craddock fue el primero en cuestionar la participación efectiva de Fernando III en la génesis de la obra: “(...) sospecho que la presunta actuación de Fernando III no es más que un mito propagado por un Rey deseoso de justificarse ante la estrepitosa derrota de toda su política legislativa” (2008, p. 155). Martin suscribe esta hipótesis y estima que Alfonso X creó una "autorité de commande” ficticia en la persona de Fernando III: “(...) le Septénaire ne témoigne en aucune façon de l'existence d'un audacieux programme de rénovation juridique dans l'esprit de Ferdinand III” (1993, p. 100).

8. Para Pérez López (2002), el setenario no tiene su origen en un modelo jurídico, sino en los textos astronómicos porque trataban del mismo número de planetas.

9. Veremos en la segunda parte de este estudio que, además de agruparse, estas leyes han sido redactadas a partir de un plan idéntico.

10. En efecto, en las Siete Partidas se evocan la antoiança y el sueño en una misma ley de la Primera Partida (I, X, 10), mientras que la fantasía se define en la Segunda (II, XIII, 8) de forma distinta a la del Setenario.

11. Las leyes II a X contienen un retrato de Fernando III (II a IX) y una alabanza a Sevilla (ley X). A la manera de las geografías antiguas, esta última propone una descripción de la ciudad (extensión territorial, nobleza, artesanía y productos, fama). En el ejemplar perdido de Gijón, había sido antepuesta a las consideraciones acerca del Rey Santo, lo cual sugiere que el fragmento detallado por Somoza constituía una especie de unidad independiente destinada a conmemorar la conquista de Sevilla por Fernando III.

12. Trataré de este tema en la segunda parte del estudio

13. Publicaré dentro de poco una concordancia entre Setenario y las Siete partidas en el volumen de estudios del proyecto 7PartidasDigital dirigido por el profesor José Manuel Fradejas Rueda (Universidad de Valladolid).

14. Traté de este tema en mi tesis doctoral, cuya publicación está en preparación.

15. Pensamos concretamente en la opinión que formuló en su tiempo Andrés Marcos Burriel, artífice del redescubrimiento del Setenario en el siglo XVIII: “(...) preciándose su autor de filósofo, abrazó la idea de dividir en siete miembros ò partes todo quanto iba tratando en períodos separados; lo que demuestra que el método pitagórico era algo del genio y gusto poco fino de este Rey" (1800, p. 217). 